\title{
Botryosphaeriaceae species associated with diseased loquat trees in Italy and description of Diplodia rosacearum sp. nov.
}

\author{
Giambra $S^{1}$, Piazza $G^{1}$, Alves $A^{2^{*}}$, Mondello $V^{1}$, Berbegal $M^{3}$, Armengol $\mathbf{J}^{3}$ and \\ Burruano $\mathrm{S}^{1}$
}

${ }^{1}$ Dipartimento di Scienze Agrarie e Forestali, Università di Palermo, Viale delle Scienze 4 - 90128 - Palermo, Italy

${ }^{2}$ Departamento de Biologia, CESAM, Universidade de Aveiro, 3810-193 Aveiro, Portugal

${ }^{3}$ Instituto Agroforestal Mediterráneo, Universitat Politècnica de València, Camino de Vera s/n, 46022 Valencia, Spain

Giambra S, Piazza G, Alves A, Mondello V, Berbegal M, Armengol J, Burruano S 2016 Botryosphaeriaceae species associated with diseased loquat trees in Italy and description of Diplodia rosacearum sp. nov. Mycosphere 7(7), 978-989, Doi 10.5943/mycosphere/si/1b/9

\begin{abstract}
Loquat (Eriobotrya japonica) is a fruit tree cultivated in several countries in the Mediterranean region. A survey of a loquat orchard in Sicily (Italy) revealed the presence of plants showing dieback symptoms and cankers with wedge-shaped necrotic sectors. Fungi from the genera Diplodia and Neofusicoccum were isolated from symptomatic plants. On the basis of morphological characters and DNA sequence data four species were identified, Neofusicoccum parvum, $N$. vitifusiforme, Diplodia seriata and a novel Diplodia species, which is here described as $D$. rosacearum sp. nov. Inoculation trials of loquat plants cv Sanfilipparo showed that $N$. parvum, $D$. seriata and $D$. rosacearum were pathogenic to this host. Although variability was observed between isolates, $N$. parvum and $D$. rosacearum were the most aggressive species.
\end{abstract}

Key words - Diplodia - Neofusicoccum - phylogeny - pathogenicity

\section{Introduction}

Loquat (Eriobotrya japonica), a species in the family Rosaceae, is a fruit tree that apparently originates from China, which is the world's largest producer. This plant has been spread worldwide and is currently cultivated in many countries. In the Mediterranean region it is cultivated in countries such as Spain, Portugal, Greece and Italy. In the latter almost its entire production is located in Sicily (Caballero \& Fernandez 2002).

This crop is affected by a number of diseases of which the most important are loquat scab, caused by Fusicladium eriobotryae (Sánchez-Torres et al. 2009), and loquat decline caused by several soilborne pathogens including Armillaria mellea, Rosellinia necatrix, Phytopththora spp. and Cylindrocarpon-like spp. (González-Domínguez et al. 2009, Agustí-Brisach et al. 2016). Also, branch canker and dieback associated with Botryosphaeriaceae species has been recently reported in the main loquat producing areas in Spain (González-Domínguez et al. 2016). Twelve different species of Botryosphaeriaceae were identified from plants with branch canker and dieback symptoms and all species were shown to be pathogenic to loquat plants (González-Domínguez et al. 2016).

Species in the family Botryosphaeriaceae are well known as important pathogens of fruit crops including, among many others, almond (Gramaje et al. 2012), olive (Lazzizera et al. 2008a), 
apple (Phillips et al. 2012) and mango (Rodríguez-Gálvez et al. 2016). However, until very recently their status as pathogens of loquat was poorly known.

In Sicily, the most important loquat producing area in Italy, plants with symptoms of branch cankers and dieback identical to those reported by González-Domínguez et al. (2016) and caused by species of Botryosphaeriaceae were observed. Thus, the aim of this work was to identify the Botryosphaeriaceae species associated with diseased loquat trees using a combination of morphological and DNA sequence data, and to evaluate the pathogenicity of the identified species to loquat plants.

\section{Materials \& Methods}

\section{Field surveys, sampling and fungal isolation}

In 2014 (May) and 2015 (March) observations were carried out in a loquat orchard located in Palermo province at $150 \mathrm{~m}$ a.s.l. (S. Maria di Gesù, $38^{\circ} 04^{\prime} \mathrm{N} ; 13^{\circ} 22^{\prime} \mathrm{E}$ ). The 25 year-old orchard extends over $10000 \mathrm{~m}^{2}$ and includes nine autochthonous cultivars (BRT20, Claudia, Fiore, La Mantia, Marcenò, Nespolone Bianco Dolce, Nespolone di Trabia, Sanfilipparo and Virticchiara) and seven allochthonous (Algerie, Bueno, El Buenet, Golden Nugget, Magdall, Peluche and Tanaka). After the preliminary observation, within three plots of $150 \mathrm{~m}^{2}$ randomly selected in March 2015, the trees with cankers were counted to determine disease incidence. During each field survey, four samples from symptomatic branches were collected from four plants as representative diseased loquats.

Symptomatic branch samples were taken to the laboratory and the outer bark was removed. To observe internal symptoms longitudinal and transversal cuts were made from samples. Wood portions were flame sterilized and fungal isolations were made from small chips cut from the margin of necrotic lesions with a sterile scalpel.

Wood chips were placed on potato dextrose agar (PDA Oxoid Ltd., Basingstoke, UK) supplemented with $0.5 \mathrm{~g} \mathrm{l}^{-1}$ of streptomycin sulphate (Sigma-Aldrich, St. Louis, MO, USA). After incubation at $25{ }^{\circ} \mathrm{C}$ in the dark for 5-7 days, hyphal tips from the margin of every putative Botryosphaeriaceae colony were sub-cultured on PDA. Isolates were stored in $15 \%$ glycerol at $80^{\circ} \mathrm{C}$ and maintained in the fungal culture collection of the Dipartimento di Scienze Agrarie e Forestali (University of Palermo). The ex-type culture of the new Diplodia species was deposited at the Centraalbureau voor Schimmelcultures (CBS), Utrecht, the Netherlands and nomenclatural data in MycoBank (Crous et al. 2004) database. The holotype was deposited in the herbarium of Instituto Nacional de Investigação Agrária e Veterinária I.P., Oeiras, Portugal (LISE).

\section{Morphological characterization}

Sporulation was induced by sub-culturing the isolates onto quarter-strength PDA ( $1 / 4$ PDA) and water agar (WA) supplemented with double-autoclaved pine needles and poplar twigs. Cultures were incubated at $23^{\circ} \mathrm{C}$ with a $12 \mathrm{~h}$ photoperiod of fluorescent lighting until pycnidia developed. Morphological identifications were based on conidial characters as described by Phillips et al. (2013).

For each isolate, cardinal temperatures for growth were determined on PDA plates incubated at $5,10,15,20,25,30,35$ and $40^{\circ} \mathrm{C}$ in the dark. Three replicates for each isolate and temperature combination were used. Colony diameters were measured along two perpendicular axes when the colonies had covered almost the entire diameter of the plate and data converted to daily radial growth (millimeters per day). Plates incubated at temperatures in which there was no growth, were transferred to $25^{\circ} \mathrm{C}$ to determine if those temperatures were fungistatic or fungicidal. For microscopy pycnidia were cut and mounted in $100 \%$ lactic acid and morphological characters of the conidia and conidiogenesis were observed with an Axioskop (Zeiss, Germany) microscope. Images were captured with an AxioCam MRc5 camera (Zeiss, Germany) and measurements made with the software AxioVision 4.6. Conidial dimensions are given as mean values of a minimum of 50 conidia with extreme values in parentheses. For other structures at least 20 measurements were made. 


\section{DNA extraction, PCR amplification and sequencing}

Genomic DNA was isolated from 1-week-old fungal cultures grown on PDA at $25^{\circ} \mathrm{C}$ in the dark using a standard CTAB-based protocol (O’Donnell et al. 1998). The internal transcribed spacer (ITS) region of the ribosomal DNA and part of the translation elongation factor 1 alpha gene (tef1- $\alpha$ ) were amplified and sequenced with primers ITS1/ITS4 (White et al. 1990) and EF1728F/EF1-986R (Carbone and Kohn 1999), respectively. PCR amplification and sequencing of amplicons was carried out as described previously (Phillips et al. 2013). Sequences were edited with FinchTV v1.4.0 (Geospiza, Inc., Seattle, Washington, USA; http://www.geospiza.com/finchtv) and compared with sequences deposited in GenBank through BLASTn searches. New sequences were deposited in GenBank (Table 1) and alignments in TreeBase (S19915).

\section{Phylogenetic analyses}

Sequences of all Diplodia species currently known from culture were retrieved from GenBank and aligned with sequences of the isolates obtained in this study. Alignments were done with ClustalX v. 1.83 (Thompson et al. 1997) using the following parameters: pairwise alignment parameters (gap opening $=10$, gap extension $=0.1$ ) and multiple alignment parameters (gap opening $=10$, gap extension $=0.2$, transition weight $=0.5$, delay divergent sequences $=25 \%$ ) . Alignments were checked and manual adjustments made if necessary using BioEdit v. 7.2.5 (Hall 1999). Maximum likelihood (ML) analyses were performed using MEGA6 (Tamura et al. 2013). The best fitting DNA evolution model was determined by MEGA6. ML analyses were performed on a Neighbour-Joining starting tree automatically generated by the software. Nearest-NeighbourInterchange (NNI) was used as the heuristic method for tree inference and 1000 bootstrap replicates were performed. The robustness of the trees was evaluated by 1000 bootstrap replications. Trees were visualized with TreeView v. 1.6.6 (Page 1996). An ITS only phylogenetic analysis was carried out because there are no tefl- $\alpha$ sequences available for the species D. huaxii, D. italica and D. pseudoplatani. To adequately resolve Diplodia species a combined ITS plus tefl- $\alpha$ phylogenetic analysis was performed.

\section{Pathogenicity test}

Pathogenicity of all isolates investigated was tested in June 2015 on 2-year-old loquat plants cv. Sanfilipparo, grown in pots. For each fungal isolate and control 10 plants were used in a randomized block experimental design. The inoculated loquat plants were kept under environmental conditions in the field.

For inoculation the bark of twigs was surface-disinfected with $70 \%$ ethanol and a piece of bark was removed with a sterile cork borer (diam. $5 \mathrm{~mm}$ ). An agar plug cut from the margin of a 6day-old colony grown on PDA at $25^{\circ} \mathrm{C}$ in the dark was placed on the wound and covered with Parafilm. Non-colonized agar plugs were used to inoculate control plants. After 3 months, the outer bark of the twigs was removed with a scalpel and the length of necrotic lesion upward and downward from the point of inoculation was measured.

To fulfil Koch's postulates attempts were made to re-isolate the inoculated fungi by transferring to PDA pieces of wood taken from the margins of each lesion. Plates were incubated at $25^{\circ} \mathrm{C}$ until fungal colonies developed. The re-isolated fungi were identified from their micromorphological characters as explained above.

\section{Statistical analyses}

Data from pathogenicity experiments were checked for normality using the Shapiro-Wilk test and subjected to one-way analysis of variance (ANOVA). Significance of differences between mean values was determined by Fisher's least significant difference (LSD) multiple range test at $P$ $=0.05$ using SAS version 9.0 (SAS Institute, Cary, NC, USA). 
Table 1 Isolates included in this study. The newly generated sequences are indicated in italics and ex-type strains in bold face.

\begin{tabular}{|c|c|c|c|c|c|}
\hline \multirow{2}{*}{ Species } & \multirow{2}{*}{ Isolate number } & \multirow{2}{*}{ Host } & \multirow{2}{*}{ Country } & \multicolumn{2}{|c|}{ GenBank } \\
\hline & & & & ITS & tef1- $\alpha$ \\
\hline \multirow[t]{2}{*}{ D. africana } & CBS 120835 & Prunus persica & South Africa & EF445343 & EF445382 \\
\hline & CBS 121104 & P. persica & South Africa & EF445344 & EF445383 \\
\hline \multirow[t]{2}{*}{ D. agrifolia } & CBS 132777 & Quercus agrifolia & USA & JN693507 & JQ517317 \\
\hline & UCROK1429 & Q. agrifolia & USA & JQ411412 & JQ512121 \\
\hline D. alatafructa & CBS 124931 & Pterocarpus angolensis & South Africa & FJ888460 & FJ888444 \\
\hline \multirow[t]{2}{*}{ D. allocellula } & CBS 130408 & Acacia karroo & South Africa & JQ239397 & JQ239384 \\
\hline & CBS 130410 & A. karroo & South Africa & JQ239399 & JQ239386 \\
\hline \multirow[t]{2}{*}{ D. bulgarica } & CBS 124254 & Malus sylvestris & Bulgaria & GQ923853 & GQ923821 \\
\hline & CBS 124135 & M. sylvestris & Bulgaria & GQ923852 & GQ923820 \\
\hline \multirow[t]{2}{*}{ D. corticola } & CBS 112549 & Quercus suber & Portugal & AY259100 & AY573227 \\
\hline & BL10 & Quercus ilex & Italy & JX894191 & JX894210 \\
\hline D. crataegicola & MFLUCC 15-0648 & Crataegus sp. & Italy & KT290244 & KT290248 \\
\hline \multirow[t]{2}{*}{ D. cupressi } & CBS 168.87 & Cupressus sempervirens & Israel & DQ458893 & DQ458878 \\
\hline & BL102 & C. sempervirens & Tunisia & KF307722 & KF318769 \\
\hline D. eriobotryicola & CBS 140851 & Eriobotrya japonica & Spain & KT240355 & KT240193 \\
\hline \multirow[t]{2}{*}{ D. fraxini } & CBS 136010 & Fraxinus angustifolia & Portugal & KF307700 & KF318747 \\
\hline & CBS 136013 & F. angustifolia & Italy & KF307710 & KF318757 \\
\hline D. galiicola & MFLUCC 15-0647 & Galium sp. & Italy & KT290245 & KT290249 \\
\hline D. huaxii & GUCC 0922-1 & Platanus sp. & China & KU848201 & - \\
\hline D. italica & MFLUCC 14-1007 & Crataegus sp. & Italy & KU848202 & - \\
\hline \multirow[t]{2}{*}{ D. intermedia } & CBS 124462 & M. sylvestris & Portugal & GQ923858 & GQ923826 \\
\hline & CBS 112556 & M. sylvestris & Portugal & AY259096 & GQ923851 \\
\hline \multirow[t]{6}{*}{ D. rosacearum } & NB7 = CBS 141915 & E. japonica & Italy & KT956270 & KU378605 \\
\hline & NB8 & E. japonica & Italy & KT956271 & KU378606 \\
\hline & NB9 & E. japonica & Italy & KT956272 & KU378607 \\
\hline & NB10 & E. japonica & Italy & KT956273 & KU378608 \\
\hline & BN-67 & E. japonica & Spain & KT240354 & KT240192 \\
\hline & CAP330 & Pyracantha coccinea & Bulgaria & GQ923881 & GQ923849 \\
\hline \multirow[t]{2}{*}{ D. insularis } & CBS 140350 & Pistacia lentiscus & Italy & KX833072 & KX833073 \\
\hline & BN-55 & E. japonica & Spain & KT240361 & KT240275 \\
\hline \multirow[t]{2}{*}{ D. malorum } & CBS 124130 & M. sylvestris & Portugal & GQ923865 & GQ923833 \\
\hline & BL127 & Populus alba & Italy & KF307717 & KF318764 \\
\hline \multirow[t]{2}{*}{ D. mutila } & CBS 136014 & P. alba & Portugal & KJ361837 & KJ361829 \\
\hline & CBS122553 & Vitis vinifera & Portugal & AY259093 & AY573219 \\
\hline \multirow[t]{2}{*}{ D. neojuniperi } & CBS 138652 & Juniperus chinensis & Thailand & KM006431 & KM006462 \\
\hline & СРC 22754 & J. chinensis & Thailand & KM006432 & КМ006463 \\
\hline \multirow[t]{2}{*}{ D. olivarum } & CBS 121887 & Olea europaea & Italy & EU392302 & EU392279 \\
\hline & CAP 257 & O. europaea & Italy & GQ923874 & GQ923842 \\
\hline D. pseudoseriata & CBS 124906 & B. salicifolius & Uruguay & EU080927 & EU863181 \\
\hline D. pseudoplatani & GUCC G603-1 & Platanus sp. & China & KU848200 & - \\
\hline \multirow[t]{2}{*}{ D. quercivora } & CBS 133852 & Quercus canariensis & Tunisia & JX894205 & JX894229 \\
\hline & CBS 133853 & Q. canariensis & Tunisia & JX894206 & JX894230 \\
\hline \multirow[t]{2}{*}{ D. rosulata } & CBS 116470 & Prunus africana & Ethiopia & EU430265 & EU430267 \\
\hline & CBS 116472 & P. africana & Ethiopia & EU430266 & EU430268 \\
\hline D. sapinea & CBS 393.84 & Pinus nigra & Netherlands & DQ458895 & DQ458880 \\
\hline
\end{tabular}




\begin{tabular}{|c|c|c|c|c|c|}
\hline \multirow{2}{*}{ Species } & \multirow{2}{*}{ Isolate number } & \multirow{2}{*}{ Host } & \multirow{2}{*}{ Country } & \multicolumn{2}{|c|}{ GenBank } \\
\hline & & & & ITS & tef1- $\alpha$ \\
\hline \multirow{3}{*}{ D. scrobiculata } & CBS 109725 & Pinus patula & Indonesia & DQ458896 & DQ458881 \\
\hline & CBS 118110 & Pinus banksiana & USA & KF766160 & KF766399 \\
\hline & CBS 109944 & Pinus greggii & Mexico & DQ458899 & DQ458884 \\
\hline \multirow{3}{*}{ D. seriata } & CBS 113423 & P. greggii & Mexico & DQ458900 & DQ458885 \\
\hline & CBS 112555 & V. vinifera & Portugal & AY259094 & AY573220 \\
\hline & CBS 119049 & $V$. vinifera & Italy & DQ458889 & DQ458874 \\
\hline \multirow{4}{*}{ D. subglobosa } & NB4 & E. japonica & Italy & KT956267 & $K U 310680$ \\
\hline & CAA502 & Fraxinus ornus & Portugal & KJ361842 & KJ361836 \\
\hline & CBS 124133 & Lonicera nigra & Spain & GQ923856 & GQ923824 \\
\hline & CBS 124131 & F. ornus & Italy & GQ923855 & GQ923823 \\
\hline D. tsugae & CBS 418.64 & Tsuga heterophylla & Canada & DQ458888 & DQ458873 \\
\hline \multirow[t]{2}{*}{ N. parvum } & NB5 & E. japonica & Italy & KT956268 & $K U 310681$ \\
\hline & NB6 & E. japonica & Italy & KT956269 & KU310682 \\
\hline \multirow[t]{3}{*}{ N. vitifusiforme } & NB1 & E. japonica & Italy & KT956264 & KU310677 \\
\hline & NB2 & E. japonica & Italy & KT956265 & $K U 310678$ \\
\hline & NB3 & E. japonica & Italy & KT956266 & KU310679 \\
\hline
\end{tabular}

Acronyms of culture collections: BL: B.T. Linaldeddu culture collection housed at Dipartimento di Agraria, Università di Sassari, Italy; CAA: Collection of Artur Alves housed at Department of Biology, University of Aveiro, Portugal; CAP, A.J.L. Phillips, Universidade Nova de Lisboa, Portugal; CBS: Centraalbureau voor Schimmelcultures, The Netherlands; CPC: Collection of Pedro Crous housed at CBS; UCROK, Department of Plant Pathology and Microbiology, University of California, Riverside; GUCC: Guizhou University Culture Collection (GUCC); MFLUCC: Mae Fah Luang University Culture Collection.

\section{Results}

\section{Field surveys, fungal isolation and identification}

Surveys of the loquat orchard revealed the presence of plants showing dieback of the branches, and cankered areas of variable size, both on stems and trunks (Fig. 1). All symptomatic plants belonged to cultivars Algerie and Bueno. No symptoms were observed on plants of other cultivars present in the orchard surveyed. Disease incidence on both cultivars was $48.5 \%$. Samples collected from diseased loquat plants showed beneath the bark brown to black vascular longitudinal discoloration and wedge-shaped necrotic sectors visible in cross sections (Fig. 1).

From the samples collected 10 botryosphaeriaceous fungi were isolated. Apart from these, the only other fungi isolated were Aspergillus spp. Identification based on morphological characters and DNA sequence from the ITS and tefl- $\alpha$ regions revealed four distinct species: Neofusicoccum parvum (2 isolates: NB5, NB6), N. vitifusiforme (3 isolates: NB1, NB2, NB3), Diplodia seriata (1 isolate: NB4) and a Diplodia sp. (4 isolates: NB7, NB8, NB9, NB10) that could not be assigned to any of the currently known species. For all species, BLAST searches showed 99-100\% similarity with reference sequences of representative strains including ex-type strains.

Diplodia species were obtained from cultivar Bueno plants only whereas Neofusicoccum species were obtained from cultivar Algerie plants only. However, symptoms caused by Neofusicoccum and Diplodia species were similar.

\section{Phylogenetic analyses}

ML analysis based on ITS sequences, although not able to discriminate clearly all species, showed that the isolates of Diplodia species from loquat were closely related to $D$. sapinea and $D$. intermedia (data not shown). Combined ITS and tef1- $\alpha$ ML analysis (Fig. 2) differentiated all Diplodia species although not all clades received high bootstrap support. The Diplodia sp. isolates in this study (NB7, NB8, NB9 and NB10) clustered with another isolate from loquat from Spain 


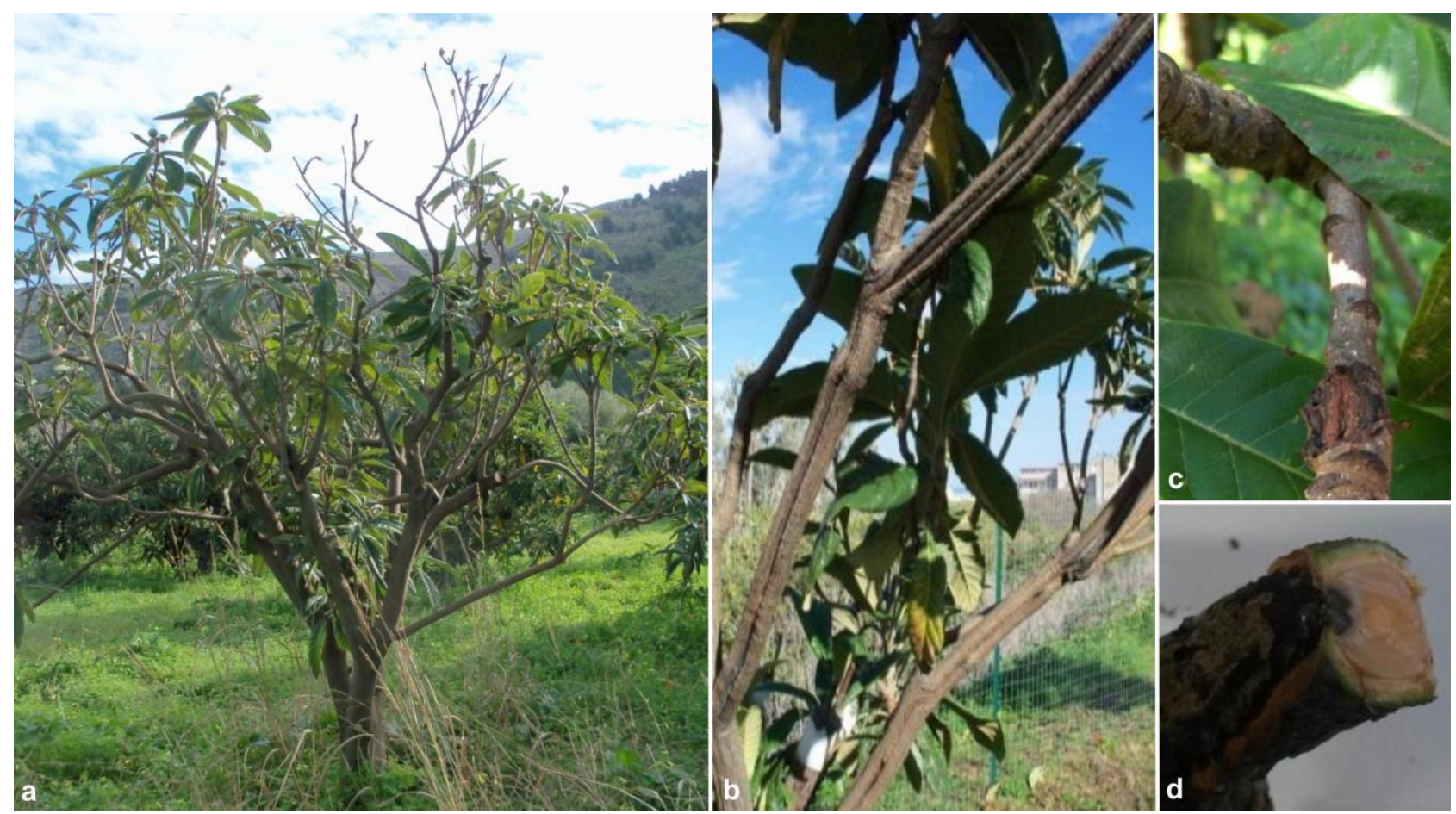

Fig. 1 - Symptoms observed on loquat plants cvs. Algerie and Bueno. a. Dieback of twigs and branches. b,c. cankers in the trunk and stems. d. cross section of a branch showing a necrotic area.

(BN-67) and an isolate from firethorn (Pyracantha coccinea) from Bulgaria (CAP330). These isolates formed a separate sub-clade, with moderate bootstrap support (62\%), within a larger clade containing the species $D$. sapinea, $D$. scrobiculata, D. seriata, D. crataegicola and D. intermedia.

\section{Taxonomy}

Diplodia rosacearum S. Giambra, A. Alves, J. Armengol \& S. Burruano, sp. nov.

Fig. 3 MycoBank: MB818575

Etymology - the epithet refers to the fact that the species has, so far, been found only in hosts from the family Rosaceae.

Sexual morph not seen. Conidiomata pycnidial, produced on poplar twigs and pine needles on $1 / 4$ strength PDA within 2 weeks, solitary or aggregated, black, globose and uniloculate. Conidiophores absent. Conidiogenous cells hyaline, smooth, cylindrical, sometimes slightly swollen at the base, holoblastic, proliferating percurrently to form distinct annellations or proliferating internally giving rise to periclinal thickenings, $(10.3-) 14.6(-19.9) \times(2.5-) 4.0(-7.80)$ $\mu \mathrm{m} ; \mathrm{n}=20$. Conidia ovoid to ellipsoid, apex obtuse, base truncate or rounded, initially hyaline becoming pigmented even while still attached to the conidiogenous cell, dark brown when mature, unicellular, but may become 1-septate when mature or more rarely when still hyaline, ellipsoid to ovoid, wall finely roughened on the inner surface, (16.1)-23.7-(31.9) $\times(9.8)-12.8-(16.7) \mu \mathrm{m},(\bar{x} \pm$ S.D. $=23.7 \pm 2.4 \times 12.8 \pm 1.1 \mu \mathrm{m}, \mathrm{L} / \mathrm{W} 1.9 \pm 0.2 ; \mathrm{n}=200)$.

Culture characteristics - Colonies on PDA filling a $90 \mathrm{~mm}$ diameter Petri dish before 7 days in the dark at $25{ }^{\circ} \mathrm{C}$. Mycelium moderately aerial initially white becoming pale grey to dark and dark in reverse.

Cardinal temperatures $-\min .<5{ }^{\circ} \mathrm{C}$, max. $>35^{\circ} \mathrm{C}$, opt. $25^{\circ} \mathrm{C}$.

Known distribution - Sicily (Italy), Valencia (Spain) and Plovdiv (Bulgaria).

Habitat - On cankered branches of Eriobotrya japonica and Pyracantha coccinea. 


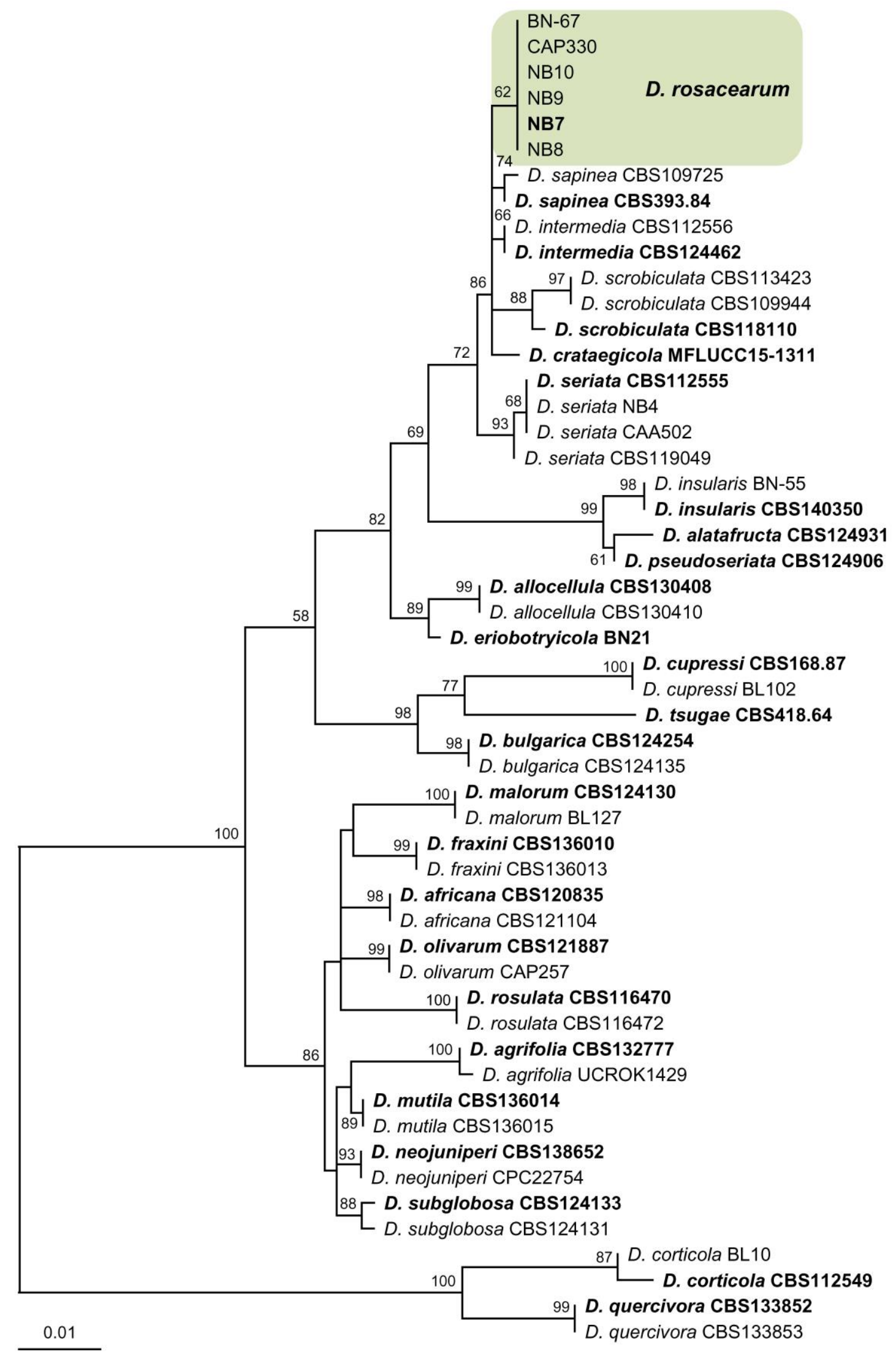

Fig. 2 - Maximum Likelihood tree of combined ITS and tefl- $\alpha$ sequence data and based on the Hasegawa-Kishino-Yano model. A discrete Gamma distribution was used to model evolutionary rate differences among sites. The tree is drawn to scale, with branch lengths measured in the number of substitutions per site. Bootstrap support values in percentage (1000 replicates) are given at the nodes. 
Material examined - Italy, Sicily (S. Maria di Gesù, $38^{\circ} 04^{\prime} \mathrm{N} ; 13^{\circ} 22^{\prime} \mathrm{E}$ ), isolated from a branch canker of Eriobotrya japonica, March 2015, Selene Giambra, HOLOTYPE LISE 96310, a dried culture sporulating on Populus tremula twigs, culture ex-holotype CBS $141915=$ NB7. Other isolates are listed in Table 1.

Notes - Diplodia rosaceraum is closely related to D. intermedia but can be distinguished by DNA sequence data and the size of conidia, which are on average larger in $D$. intermedia.

\section{Pathogenicity test}

Three months after inoculation stems showed external cankers and subcortical dark-brown discoloration spreading upward and downward from the inoculation point. Moreover, some of the symptomatic plants also reacted by issuing new shoots below the point of inoculation. No discoloration was observed in the stems of control plants as well as in plants inoculated with $N$. vitifusiforme isolates NB2 and NB3.

Average lesion lengths differed significantly $\left(\mathrm{F}_{7,28}=14.02 ; P<0.001\right)$ between species and isolates tested (Fig. 4). The largest lesions were caused by $N$. parvum isolate NB5 (74.1 mm), followed by D. rosacearum NB8 and NB10 isolates $(59.9 \mathrm{~mm}$ and $45.6 \mathrm{~mm}$, respectively). The smallest lesions, ranging between $12.2 \mathrm{~mm}$ and $22.3 \mathrm{~mm}$, were caused by $N$. vitifusiforme (isolate NB1) and D. seriata (isolate NB4). All fungal species tested were successfully re-isolated from inoculated plants, thus fulfilling Koch's postulates. No fungal pathogens were isolated from control plants.

\section{Discussion}

The aetiology of canker and dieback symptoms on loquat plants was studied in an orchard in Sicily, the main Italian loquat producing area. Four Botryosphaeriaceae species belonging to the genera Diplodia and Neofusicoccum were identified. These included N. parvum, N. vitifusiforme, D. seriata and a novel species here described as Diplodia rosacearum.

In a previous study (González-Domínguez et al. 2016) twelve species of Botryosphaeriaceae belonging to the genera Diplodia, Dothiorella, Neofusicoccum, and Spencermartinsia were identified from loquat plants showing canker and dieback symptoms in Spain. This represents a much greater diversity than the one presented here. However, in that previous study, field surveys covered 36 loquat orchards located in six different provinces of Spain. It is possible that a wider survey of a larger number of orchards in Sicily would reveal more species of Botryosphaeriaceae.

Of the four species found $N$. vitifusiforme is reported for the first time on loquat. This species has been previously found in Italy on olive (Lazzizera et al. 2008b) and grapevine (Mondello et al. 2013). Neofusicoccum parvum and D. seriata are cosmopolitan species known to occur on a very wide range of hosts (Phillips et al. 2013) and have been previously reported on loquat in Spain (González-Domínguez et al. 2016). In the survey performed by GonzálezDomínguez et al. (2016) D. seriata was the most prevalent species isolated from loquat cankers. On the contrary, notwithstanding the small number of isolates obtained in this study, D. seriata was not the most frequent species. Nevertheless, $D$. seriata appears to be an important pathogen on loquat. This is further reinforced by the recent report of this fungus as a postharvest pathogen of loquat fruit (Palou et al. 2013).

A new Diplodia species was described here. This species was first isolated from firethorn by Phillips et al. (2012) who recognized differences between it (Diplodia sp. isolate CAP330) and $D$. intermedia, but chose not to introduce a new species until more isolates were available. More recently, González-Domínguez et al. (2016) isolated a Diplodia sp. (isolate BN-67) from loquat plants in Spain that was closely related to the one reported by Phillips et al. (2012) but did not provide a formal description of the species. Our study confirms that the Diplodia sp. obtained here and those previously reported on firethorn in Bulgaria and loquat in Spain represent a distinct species for which the name D. rosacearum is introduced. 


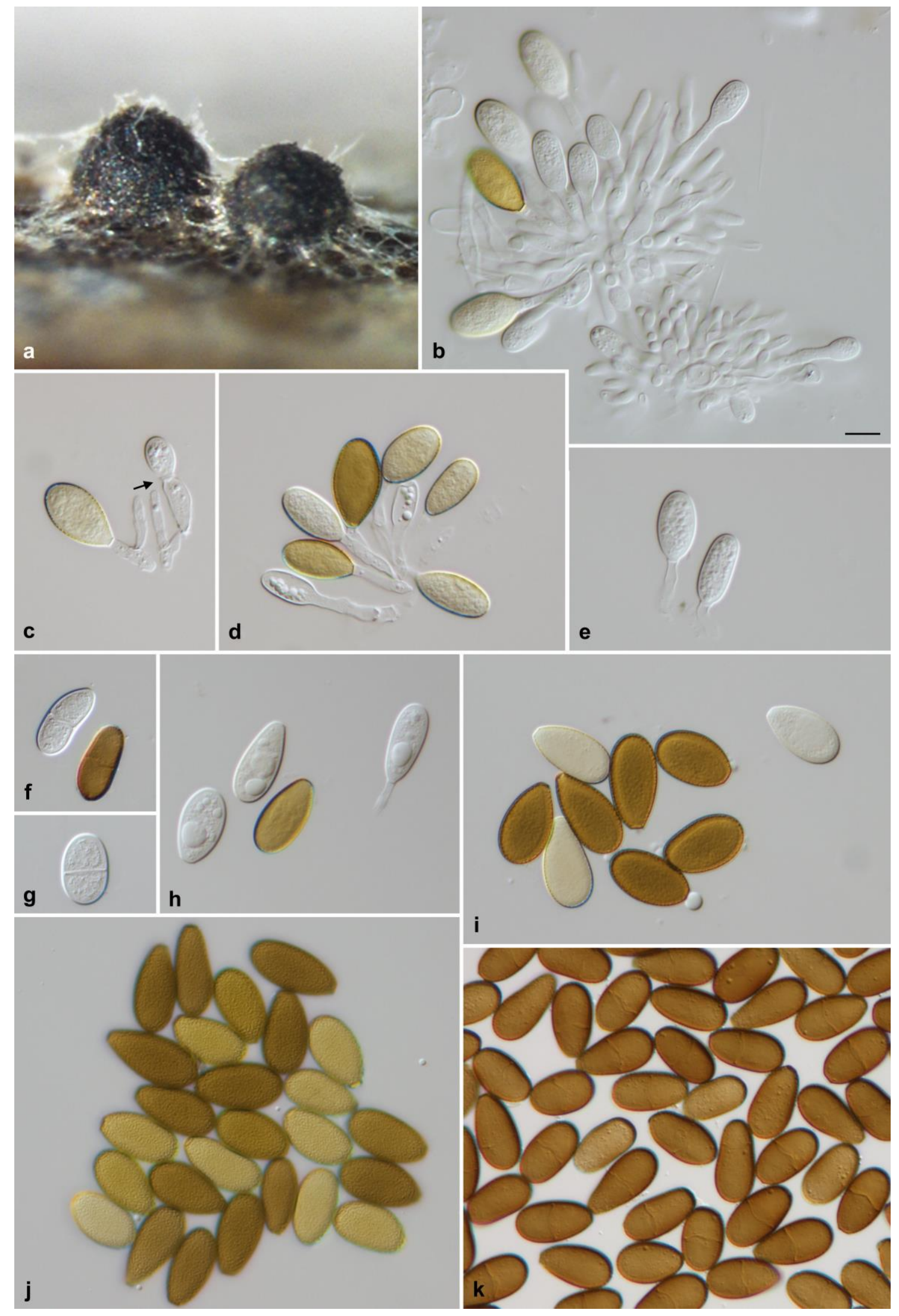

Fig. 3 - Diplodia rosacearum NB7 (CBS 141915). a. pycnidia formed on poplar twigs. b. conidia developing on conidiogenous cells. c,d,e. conidia attached to conidiogenous cell, arrow indicates annellations. f,g. hyaline septate and brown septate conidia. h,i. conidia showing several stages of colour development. $\mathbf{j}$. conidia showing verruculose inner surface of the wall. k. mature brown aseptate and 1-septate conidia. Scale bar: $\mathrm{b}-\mathrm{k}=10 \mu \mathrm{m}$. 


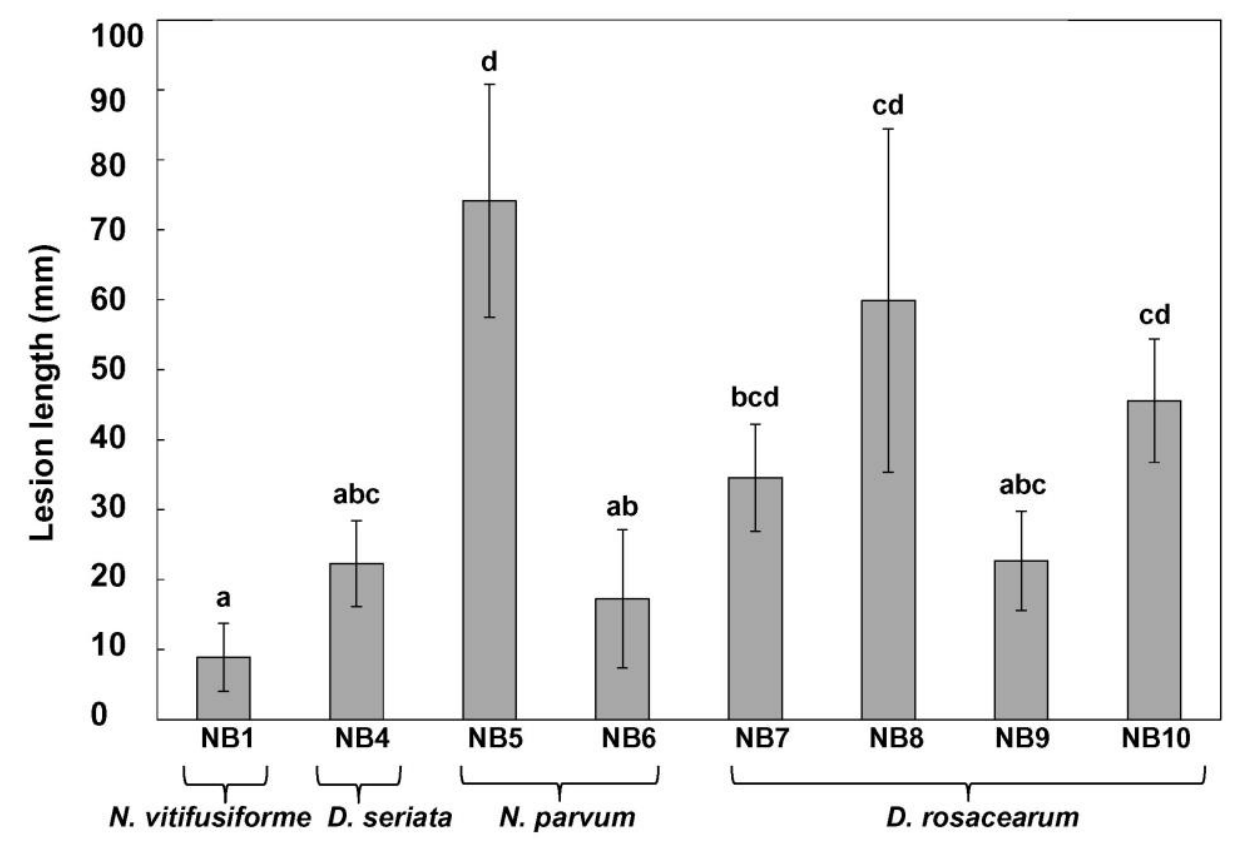

Fig. 4 - Mean internal lesion length (mm) in stems of loquat plants cv. Sanfilipparo inoculated with isolates of $D$. rosacearum, $D$. seriata, $N$. parvum and $N$. vitifusiforme. The vertical lines indicate standard errors. Bars with the same letter do not differ significantly according to Fisher's LSD test $(P<0.05)$.

Although some differences in aggressiveness were detected between isolates, $N$. parvum, $D$. seriata and $D$. rosacearum caused larger necrotic lesions on inoculated plants than $N$. vitifusiforme. In this last species two of the three isolates tested caused no lesions on inoculated plants, thus suggesting that $N$. vitifusiforme is non-pathogenic or weakly pathogenic to loquat. However, future studies with more isolates should be performed to confirm this. Diplodia rosacearum was the most aggressive of the species tested, which is in agreement with the report of González-Domínguez et al. (2016). In their study, D. rosacearum (as Diplodia sp.) was the most aggressive species causing death of all inoculated plants.

In the orchard surveyed only plants from cultivars Algerie and Bueno showed disease symptoms, although several different cultivars were present. This suggests that there may be some variation in susceptibility among cultivars, with cultivars Algerie and Bueno being apparently more susceptible. However, more studies are needed to confirm this hypothesis. Nevertheless, all species were shown to be pathogenic to cultivar Sanfilipparo in artificial inoculation assays.

Additionally there was some apparent cultivar preference among the fungal species found with Neofusicoccum species occurring on cultivar Algerie plants only and Diplodia species occurring on cultivar Bueno plants only. However, the isolates studied were obtained from a small number of plants and it is thus necessary to carry out a wider sampling in order to evaluate if this cultivar preference is not an artifact. Besides, Diplodia species have been shown to be pathogenic to cultivar Algerie plants with D. rosacearum being highly aggressive (González-Domínguez et al. 2016).

It is interesting to notice that although loquat is a native and important crop in Asia there are no reports of Botryosphaeriaceae species affecting loquat from that part of the world. It is not known if these fungi have passed unnoticed in previous studies or if they are emerging as pathogens of this host. Nevertheless, this study and previous ones (González-Domínguez et al. 2016, Palou et al. 2013) show that species in the Botryosphaeriaceae should be considered as important pathogens of loquat. More studies should be carried out in other loquat growing regions to estimate the overall diversity and pathogenicity of these fungi. In particular, the new species $D$. rosacearum due to its apparent high aggressiveness deserves more attention on loquat as well as other hosts in the Rosaceae. 


\section{Acknowledgements}

This research was supported by Servizio VII Fitosanitario Forestale del Dipartimento Regionale, Azienda Regionale Foreste Demaniali. Artur Alves acknowledges financing by European Funds through COMPETE and by National Funds through the Portuguese Foundation for Science and Technology (FCT) to the research unit CESAM (UID/AMB/50017/2013 - POCI-010145-FEDER-007638) and himself (FCT Investigator Programme - IF/00835/2013), and support by the Contributi avvio e sviluppo collaborazioni internazionali (CORI-2014), Visiting Professor Programme at the University of Palermo, Italy. The authors thank Dr. Giuseppe Lo Giudice for allowing carrying out the surveys in his loquat field.

\section{References}

Agustí-Brisach C, Cabral A, González-Domínguez E, Pérez-Sierra A, León M, Abad-Campos P, García-Jiménez J, Oliveira H, Armengol J. 2016 - Characterization of Cylindrodendrum, Dactylonectria and Ilyonectria isolates associated with loquat decline in Spain, with description of Cylindrodendrum alicantinum sp. nov. European Journal of Plant Pathology $145,103-118$.

Caballero P, Fernández MA, 2002 - Loquat, production and market. Options Méditerranéennes Serie A 58, 11-20.

Carbone I, Kohn LM, 1999 - A method for designing primer sets for speciation studies in filamentous ascomycetes. Mycologia 91, 553-556.

Crous PW, Gams W, Stalpers JA, Robert V, Stegehuis G. 2004 - MycoBank: an online initiative to launch mycology into the $21^{\text {st }}$ century. Studies in Mycology 50, 19-22.

González-Domínguez E, Alves A, León M, Armengol J. 2016 - Characterization of Botryosphaeriaceae species associated with diseased loquat (Eriobotrya japonica) in Spain. Plant Pathology (doi: 10.1111/ppa.12556).

González-Domínguez E, Pérez-Sierra A, Álvarez A, León M, Abad-Campos P, Armengol J, García-Jiménez J. 2009 - Agentes fúngicos presentes en plantaciones de nísperos (Eriobotrya japonica Lindl.) con síntomas de decaimiento en la provincia de Alicante. Boletín de Sanidad Vegetal y Plagas 35, 453-467.

Gramaje D, Agustí-Brisach C, Pérez-Sierra A, Moralejo E, Olmo D, Mostert L, Damm U, Armengol J. 2012 - Fungal trunk pathogens associated with wood decay of almond trees on Mallorca (Spain). Persoonia 28, 1-13.

Lazzizera C, Frisullo S, Alves A, Lopes J, Phillips AJL. 2008a - Phylogeny and morphology of Diplodia species on olives in southern Italy and description of Diplodia olivarum. Fungal Diversity 31, 63-71.

Lazzizera C, Frisullo S, Alves A, Phillips AJL. 2008b - Morphology, phylogeny and pathogenicity of Botryosphaeria and Neofusicoccum species associated with drupe rot of olives in southern Italy. Plant Pathology 57, 948-956.

Mondello V, Lo Piccolo S, Conigliaro G, Alfonzo A, Torta L, Burruano S. 2013 - First report of Neofusicoccum vitifusiforme and presence of the Botryosphaeriaceae species associated with Botryosphaeria dieback of grapevine in Sicily (Italy). Phytopathologia Mediterranea 52, 388-396.

O’Donnell K, Cigelnik E, Nirenberg HI. 1998 - Molecular systematics and phylogeography of the Gibberella fujikuroi species complex. Mycologia 90, 465-493.

Page, R. D. 1996 - TreeView: an application to display phylogenetic trees on personal computers. Computer Applications in the Biosciences, 12, 357-358.

Palou L, Taberner V, Montesinos-Herrero C. 2013 - First report of Diplodia seriata causing loquat fruit rot in Spain. Plant Disease 97, 421-422.

Phillips AJL, Alves A, Abdollahzadeh J, Slippers B, Wingfield MJ, Groenewald JZ, Crous PW 2013 - The Botryosphaeriaceae: genera and species known from culture. Studies in Mycology 76, 51-167. 
Phillips AJL, Lopes J, Abdollahzadeh J, Bobev S, Alves A. 2012 - Resolving the Diplodia complex on apple and other Rosaceae hosts. Persoonia 29, 29-38.

Rodríguez-Gálvez E, Guerrero P, Barradas C, Crous PW, Alves A. 2016 - Phylogeny and pathogenicity of Lasiodiplodia species associated with dieback of mango in Peru. Fungal Biology doi 10.1016/j.funbio.2016.06.004

Sánchez-Torres P, Hinarejos R, Tuset JJ, 2009 - Characterization and pathogenicity of Fusicladium eriobotryae, the fungal pathogen responsible for loquat scab. Plant Disease 93, 1151-1157.

Tamura K, Stecher G, Peterson D, Filipski A, Kumar S. 2013 - MEGA6: molecular evolutionary genetics analysis version 6.0. Molecular Biology and Evolution 30, 2725-2729.

Thompson JD, Gibson TJ, Plewniak F, Jeanmougin F, and Higgins DG. 1997 - The ClustalX windows interface: flexible strategies for multiple sequence alignment aided by quality analysis tools. Nucleic Acids Research 25, 4876-4882.

White TJ, Bruns T, Lee S, Taylor J. 1990 - Amplification and direct sequencing of fungal ribosomal RNA genes for phylogenetics. In: PCR Protocols, a Guide to Methods and Applications (eds. MA Innis, DH Gelfand, JJ Sninsky and J White) Academic Press. San Diego, Ca, USA 315-322. 